\title{
LIEZEL CILLIERS
}

\section{REIMPLEMENTING TELEMEDICINE IN THE EASTERN CAPE ${ }^{1}$}

Mr Benton Alexander, Director of eHealth in the Eastern Cape Department of Health, reflected on his 20th year in the position. During his tenure, various telemedicine projects had been implemented in the Eastern Cape Department of Health (ECDoH). The most successful of these projects had been the teleradiology programme, which was established in response to the shortage of radiologists in the province. X-ray images were sent remotely from 23 urban and rural hospitals to private radiologists located around the country. The radiologists assessed the X-rays and wrote a radiology report that was then transmitted back to the referral hospital. This process was usually completed within a 3-hour turnaround time, meaning that patients did not have to travel long distances to the nearest tertiary hospital, and did not have to wait weeks for their results. Furthermore, it was reported that $75 \%$ of unnecessary radiology referrals were prevented after the implementation of the teleradiology programme.

While teleradiology had become the flagship project of telemedicine in South Africa, other telemedicine services did not fare as well. The Minister of Health stated in 2010 that of the 86 telemedicine sites implemented by the government since 2000, less than a third were still functional. The original National Telemedicine Strategic Plan that was tabled in 1999 envisioned three phases during which telemedicine would be rolled out across South Africa. The first phase was declared a failure after three years, and this led to the National Government's decision to cancel the subsequent phases. Only 15 years later did the National Government express interest again in telemedicine. In order to facilitate the implementation process, the National eHealth Policy and a new National Telemedicine Strategy were developed. As teleradiology was a decade earlier the most successful programme during phase 1 , it was decided that the programme would be the initial focus of telemedicine services.

Mr Alexander was tasked with rolling out telemedicine in the Eastern Cape as his experience with the initial project was deemed to be invaluable. He had been asked by the ECDoH to investigate the reasons behind the past failure of telemedicine in the province. He felt that most of the factors he had identified were within his power to correct, but there was one concern that worried him. There remained uncertainty among doctors as to who was ultimately responsible for the care of the patient: Is it the referring doctor that must administer the treatment to the patient, or the specialist prescribing a course of treatment without ever having physically examined the patient? How could the privacy of the patient be protected during telemedicine consultations? What legal framework needed to be applied to determine negligence of care?

\footnotetext{
${ }^{1}$ Copyright $@$ ( 2018, Liezel Cilliers. This case was prepared for the purpose of class discussion. Names and some information have been disguised. This case is published under a Creative Commons BY-NC license and originally appeared as a chapter in Transforming Society Using ICT: Contemporary Discussion Cases from Africa. Permission is granted to copy and distribute this case for non-commercial purposes, in both printed and electronic formats.
} 


\section{Background}

The Eastern Cape Province was the second largest province located on the southeastern coast of South Africa. The province had a land area of 168,966 km², which constituted approximately $14 \%$ of the total land area of the country. Sixty-five percent of the population in this province lived in rural areas. The Eastern Cape Province was one of the poorest and most rural provinces in South Africa. The general socio-economic conditions in the province were considered to be poor with the unemployment rate at $28 \%$; also, $57 \%$ of the population were reported to be living below the poverty line (StatsSA, 2012).

The ECDoH provided health services to the citizens in the province. These services were provided through a three-tier system. The first tier was the community health centres (CHC) in the District Health System. Primary healthcare provided at these centres included comprehensive services to communities with an emphasis on disease prevention, health promotion and community participation. Typical primary healthcare services included preventative and curative services such as mother and child health, immunisations, preventative screening, family planning, and treatment of acute and chronic conditions in the community. Patients that could not be treated at the CHCs were referred to the second tier, that is the district hospitals, for more comprehensive care or the third tier, the tertiary hospitals, for specialist care (O’Mahony, Wright, Yogeswaran, \& Govere, 2014; Cilliers \& Flowerday, 2014). The province had 762 primary health care clinics, 60 community health care centres, 63 district hospitals, 11 regional hospitals, 12 specialised hospitals and one tertiary teaching hospital. While these facilities seemed adequate, the patient to doctor ratio in the province was nine medical practitioners per 100000 population. The ratio for specialists was even less, with only one registered dermatologist for the entire province (Mxoli, MostertPhipps, \& Gerber, 2014).

The ECDoH provided health services for the ‘quadruple burden of disease' (HIV/AIDS and tuberculosis, maternal and child mortality, non-communicable diseases, and injury and violence). Health service delivery was negatively affected by this burden of diseases, and this meant that the Department had to find innovative ways of making use of existing resources more effectively (Yerramilli, 2015). As a large part of the community lived in rural communities, health care services needed to be moved into these communities. Typical healthcare problems reported in the rural communities included chronic lifestylerelated diseases such as diabetes, hypertension and HIV/AIDS, high rate of maternal deaths and preventable deaths such as mental illness/neuropsychiatric disorders, violence and motor vehicle accidents (Yerramilli, 2015; Cilliers \& Flowerday, 2014). For these reasons, the Eastern Cape Province was chosen as one of the sites where telemedicine was rolled out to increase the access to health care among the population.

\section{Telemedicine}

The World Health Organisation (WHO) defined e-Health as "the use of information and communication technologies for health to treat patients, pursue research, educate students, track diseases and monitor public health" (WHO, 2012, p.1). e-Health was a broad term and included services such as electronic health records, mobile health, consumer health informatics, telemedicine and virtual healthcare.

Telemedicine was identified by the WHO as a possible tool to improve access to health care services in the rural areas of developing countries. Telemedicine, meaning 'medicine at a distance', could be used to extend the accessibility of health care in the most under-serviced areas of the Eastern Cape (Cilliers \& Flowerday, 2014). Therefore, telemedicine became an integral part of the national Department of Health's e-Health strategy in South Africa, with millions of rands being invested in various telemedicine projects since 1999 (Motsoaledi, 2010).

Two methods were available for the delivery of telemedicine services: real-time approach and the asynchronous approach (also known as the store and forward approach). Due to connectivity problems, 
when telemedicine was first introduced in the province, the most popular method was the second approach-where a message was sent to the specialist to review later or at their convenience. For this approach to be adopted, all that was needed was a basic computer with Internet connectivity and a camera (Cilliers \& Flowerday, 2011, 2012).

Telemedicine could be used in a variety of health disciplines to provide services to rural communities. These services included teleradiology, telepathology, teleconsultation, telediagnosis and monitoring telepsychiatry, teledermatology, tele-emergency, telesurveillance, telepharmacy, telecardiology, teleendoscopy, teledentistry, teledialysis, tele-education, prison telemedicine, military telemedicine and telesurgery including robotic surgery.

\section{Ethical Considerations in Telemedicine}

In 2005, telemedicine consultations comprised three-thousandths of one percent of all medical consultations worldwide (Gorea, 2005). While the technology to enable telemedicine has become common place, the legal and ethical issues associated with this type of medical care lagged behind. Typical legal concerns that were reported by health care workers included how to obtain informed consent for a telemedicine consultation, how telemedicine will affect the relationship between the doctor and patient, how to maintain the privacy of the patient's information and consultation online as well as who is ultimately responsible for care in an international, cross-border consultations.

After the WHO proclaimed telemedicine to be of great benefit to improve health care in developing countries in 1995, many countries decided to include the technology in their health care programmes. While the technology was available, very little attention was given to the particular requirements that developing countries would need to implement telemedicine successfully. Social, ethical and legal matters concerning telemedicine naturally became an afterthought. This meant that the legislation that was required to govern the patient-doctor relationship during telemedicine consultations was left to 'catch up' with the technology.

Along with the proclamation that telemedicine would be of great benefit to improve the quality and access of health care in developing countries, the WHO did acknowledge that these services must be offered in such a way that respects the principle of equality and differences in culture, education, language, physical and mental ability and geographic location. The WHO decided not to address the specific ethical question related to telemedicine, thus leaving individual countries to develop their guidelines and legislature around the issue.

Some of the medico-legal questions raised with telemedicine include whether health care workers should be required to obtain an exclusive licence to practice telemedicine, who is responsible for the initial diagnosis of the patient, and the subsequent continuum of care. These issues are especially important where telemedicine is used to provide health care services to vulnerable groups, such as children, and when practised across international borders. The ethical issues raised by health care workers when they use telemedicine include informed consent, the privacy of the patient's information, the standard of care due to the lack of face-to-face consultation, and the ability of the consulting doctor to perform a physical examination on the patient.

Despite its potential benefits, wherever telemedicine was practised many ethical and legal considerations needed to be taken into account. Among the most significant issues were privacy, the standard of care, informed consent, professional negligence and reimbursement. 


\section{Privacy}

Historically, the most common ethical oath associated with the medical profession was the Hippocratic Oath, translated from Greek in approximately 400 B.C:

Whatever I see or hear in the lives of my patients, whether in connection with my professional practice or not, which ought not to be spoken of outside, I will keep secret, as considering all such things to be private (Anonymous, n.d).

This Oath meant that it was a doctor's duty to ensure that a patient's privacy was honoured. Privacy was not necessarily complete, however. In some situations, the physician might share the information with other healthcare workers if they deemed it in the best interest of the patient. An example of such a situation was if the doctor felt the patient was a danger to themselves or if the underlying condition would determine how the patient was treated by another health care worker. With this caveat in mind, all patients had the right to privacy in the context of telemedicine (see Exhibit 1).

The type of treatment sought by the patient was likely to affect the sensitivity to the breach of privacy in the above cases. A patient that was seeking treatment for conditions that were stigmatised, such as HIV/AIDS or mental health, were more likely to experience adverse effects if their information was made public that if a routine X-ray for a broken bone is revealed. However, telemedicine involved all of these categories of privacy during the consultation and afterwards when information was stored either digitally or in a paper-based file.

\section{Standard of care}

The relationship between doctor and patient was unique and was a prerequisite for the establishment of a duty of care. Telemedicine could enhance the standard of health care in rural areas as patients did not have to travel great distances to the next tier of healthcare facility while nevertheless receiving their results or diagnosis faster than ever before.

The use of telemedicine challenged the traditional perception of the patient-physician relationship. First, telemedicine required a new definition of what entails the quality standard of health care. It had been suggested that the standard of health care when making use of telemedicine was defined by the unique characteristics of telemedicine. These characteristics include the location of the expert, their speciality and the ICT media being used to connect the referring and specialist doctors. Secondly, the traditional patient-doctor relationship was not applicable as a face-to-face consultation was no longer required for a diagnosis. Instead, the management of the patient might be directed by a health care worker with whom they would have no direct contact or communication. This issue raised concerns about how informed consent could be obtained and who would be responsible for the medical treatment and record keeping of the patient.

\section{Informed consent}

Informed consent speaks to the right of autonomy of the patient and should be obtained before any medical encounter, whether it is face-to-face or at a distance. Informed consent was also necessary to inform the patient of any benefits, consequences or risks that they might face with a particular treatment. This consent could be in written form or given verbally by the patient. Many health care workers raised their concern as to whether the consent for telemedicine was practically possible.

\section{Professional negligence}

The question as to who was responsible for the care of the patient had become an important issue when considering the ethical and legal implications of telemedicine. The answer to this question was likely to determine who would be responsible when professional negligence needed to be proven by the patient. 
Health care workers received very little information about telemedicine in their undergraduate curriculum. Where it was included, the topic was dealt with theoretically without any training on how to use the technology or how to determine the quality of the care provided. This lack of training could increase the risk that actions would be judged to be negligent.

\section{Reimbursement}

A practical issue facing many telemedicine implementation was billing and the division of payments. The matter was complicated by the presence of two or more healthcare providers in the telemedicine interaction. If only one party received reimbursement, health care workers in the other party would likely not want to participate in the service. This could lead to a situation where face-to-face consultations were preferred even if superior telemedicine services are available. Investors would also choose not to invest in the technology if there was no way to recover their costs.

\section{Telemedicine in South Africa}

The national Department of Health (DoH) set up the National Telemedicine Task Team (NTTT) in 1998 to establish telemedicine in South Africa. The purpose of the NTTT was to coordinate the introduction of the South African Telemedicine System into the South African health care delivery system.

The National Telemedicine Project was implemented in 3 phases over a period of five years.

PHASE I: April 1999 to March 2001 - 28 pilot projects across six provincial sites were rolled out. The services these projects provided included teleradiology, tele-ultrasound, telepathology, teleophthalmology.

PHASE II: April 2001 to March 2002 - involved the development of an effective telemedicine connection between 75 sites. The network was to be divided into various provincial networks for management purposes.

PHASE III: April 2002 to March 2004 - additional sites were developed as the need arose. The original sites were transformed from pilot sites into fully operational clinical sites.

The first phase of the National Telemedicine Strategic Plan commenced as planned but was deemed unsuccessful. At the 1st South African Telemedicine Conference in 2010, Minister of Health Aaron Motsoaledi reported that of the 86 telemedicine projects implemented by the government since 2000, less than a third were still functional (Motsoaledi, 2010). Due to the high failure rate of telemedicine services implemented during the 1st phase of the National Telemedicine Strategic Plan, it was decided not to initiate phases two and three of the plan.

\section{Telemedicine in the Eastern Cape}

Mr Alexander was involved with the implementation of the first telemedicine sites in 1999 in the Eastern Cape Province. After a needs analysis was undertaken, it was decided that the area that would benefit the most from telemedicine be the former Transkei area. A variety of telemedicine services were introduced in this area over the next two years. The report of these services was presented by a Dr Banach at the $1^{\text {st }}$ International Telemedicine conference to be held in the Ukraine in 2007 (Banch, 2007). What follows is an extract of the paper that was presented. 


\section{CILLIERS}

\section{Pathology and dermatology}

The Walter Sisulu University (formerly known as UNITRA) partnered with the Armed Forces Institute of Pathology (IFIP) in Washington DC, USA, to provide a static, Internet based pathology service. The project ended in 2003. The service was run with an asynchronous computer system that allowed the pathologists at IFIP to review pathology data in their spare time. Reports were then sent back to the doctor in South Africa with a possible diagnosis.

A second pathology project was initiated in 1999, providing cytology and pathology support between St Elizabeth Hospital in Lusikisiki and the Mthatha Academic Hospital complex. Cytology services included analysis of fluid, sputum samples and imprint or smears of tumours. Haematology services included analysis of blood and bone marrow smears. The workstation at St Elizabeth Hospital consisted of a Zeiss Axioplan Microscope with a Sony 3CCD camera, a PC with MediRad software, an X-ray scanner to support pathology examination, and video phone for real-time video conferencing that included a $128 \mathrm{~kb}$ ISDN communication line. In 2006, the DoH introduced the Coolscope microscope for pathology services in the province. The microscope allowed pathology services in Mthatha, East London and Port Elizabeth to communicate, share expertise and provide training.

\section{Radiology}

The Rietvlei Hospital Project was started in 1999 and focused on teleradiology services. Rietvlei Hospital was located in a very rural area of the former Transkei area. The project connected health care workers at the hospital with specialists at the Mthatha Academic Hospital complex to consult on orthopaedic and childhood congenital cases.

\section{Tele-education}

Videoconferencing facilities for tele-education were made available in 2000 in the province. Videoconferencing facilities linked the province's four health resource centres with the seven medical schools in South Africa. The facilities made use of a $512 \mathrm{~kb}$ line and were mostly employed for workshops, meetings, conferences and interviews.

Telemedicine services flourished in the late 1990s and early 2000s, but very few of these pilot projects survived the new millennium. In preparation for his new project, Mr Alexander had read academic papers and had many discussions with doctors as to why they thought the telemedicine pilot projects failed to convert into sustainable services. The following challenges were often mentioned as being responsible for these failures. Technical challenges included poor infrastructure in rural hospitals, which sometimes prevented access to the telemedicine units. Some of the doctors pointed out that the units were locked away in the manager's office for safe keeping, which discouraged incorporating telemedicine into the work flow of the clinic. Poor information and communication technology (ICT) infrastructure that was typical of rural areas-such as a lack of power, poor telecommunication lines with limited Internet access and bandwidth - further discouraged the use of the service. Power surges and lighting also damaged the receivers and frequently prevented Internet access in the rural areas.

Social challenges included a lack of necessary computer literacy skills to operate these units among some of the doctors and nurses in the clinics. This lack of technical expertise was further compounded by the lack of training for staff on how to use the telemedicine units as well as the lack of ICT support. If something went wrong, the staff did not have the skills to fix the problem, and there was no helpdesk to ask for assistance.

Mr Alexander further found that the top-down approach that was taken by the national DoH and ECDoH did not endear the telemedicine services to the health care workers. The health care workers felt that they were not consulted on the matter and subsequently had no input into the design of the service or how it 
was incorporated into the workflow of the clinic. One of the doctors summarised this sentiment as 'Do it with us NOT for us'.

The primary concern that was mentioned most often by the doctors, however, was that legal and ethical regulations did not keep up with the development of the technology. While the national DoH did start work on a telemedicine policy for South Africa in 1999, this policy was never completed and was subsequently replaced by the more general e-Health policy for South Africa in 2012.

Legal and ethical concerns of the health care workers included the privacy of patients, as well as the legal liability for providing a diagnosis, treatment and even prescription when the doctor had never met the patient and was not able to independently determine a full medical history. One of the articles that $\mathrm{Mr}$ Alexander read provided a convenient example: 'There's still no legislative provision for doctors to use digital signatures on prescriptions' (Prinsloo, 2015).

\section{Ethical Issues in South African Telemedicine}

In South Africa, telephone based telemedicine services have been available since 2011. However, these services were found to be unethical and unlawful according to the Medical Protection Society in South Africa, which indicated that 'It is highly unlikely that Society will assist a member, who is registered with the Health Professions Council of South Africa (HPCSA), with any problems that arise from their participation in telemedicine in South Africa' (Mars \& Jack, 2012). While South Africa generally faced the same categories of issues regarding telemedicine, many aspects were specific to the country.

\section{Privacy}

The right to privacy was enshrined in the South African Constitution of 1996, Section 14, (d), which stated that "Everyone has the right to privacy, which includes the right not to have the privacy of their communications infringed.” This implied that the onus was on the health care worker or the national DoH to ensure that patients' data were transmitted and stored securely. This recommendation was supported by the World Medical Association that stated: "Due to the risks of information breaches that are inherent to some types of electronic communication, the doctor has an active obligation to ensure that all established standards of security measures have been followed to protect the patient's confidentiality" (Mars \& Jack, 2012, p.10) However, while many of the health care workers that Mr Alexander spoke to agreed that telemedicine should keep the patient's information confidential, they also had a concern that the system must provide immediate access to authorised staff to view these records. If the information was not available, it was of no use to health care workers.

A variety of safeguards could be put in place to prevent unauthorised access to the patient's information. Passwords or other authentication methods could be employed to limit access to authorised health care workers to maintain or add to the file. When the asynchronous telemedicine service was used, protections would be needed to ensure that the health care worker sent the information to the right e-mail address. Encryption could be used to protect these e-mails. Modern videoconferencing equipment encoded the data being transmitted, limiting the risk of unauthorised access to confidential information. Electronic audit trails could potentially detect unauthorised usage of the system; encryption and return receipts could verify that information was not lost along the way. Mr Alexander's primary concern in this regard was that information technology staff with the necessary skill to put these measures in place were not necessarily in place in the public service. 


\section{Standard of health care}

There were prescribed international standards for the transmission and compression of digitised X-ray films, but these standards were not achievable with commercially available digital cameras. If a doctor in a rural hospital in the Eastern Cape Province, with only fundamental X-ray equipment, were to take a photograph of an X-ray plate with one of these commercial digital cameras and e-mail it to a radiologist for interpretation, would this comply with the acceptable standard of care within the resource-constrained environment? Furthermore, if the rural doctor received the report from the radiologist, which would be responsible for the outcome of the management plan and the record keeping of the electronic consultation? The radiologist could claim that the quality of the photograph was inferior and he could have missed something, while the rural doctor could state that he/she did the best they could within the circumstances and prevented the patient from travelling for hours to receive treatment.

Also, there was currently no provision in South African law for electronic signatures. That meant that both the referring health practitioner and the specialist would need to keep adequate records of all aspects of the case including the findings and recommendations of the telemedicine consultation.

\section{Informed consent}

While Mr Alexander knew that acquiring informed consent before taking any medical action was good practice, concerns were surrounding this matter. Prior research conducted in Kwa-Zulu Natal revealed that less than $10 \%$ of doctors obtained written informed consent before treating a patient, while $61.1 \%$ did not ask for any consent when they communicated with patients via e-mail (Mars \& Jack, 2012).

In South Africa, the HPCSA proposed guidelines that required written informed consent to be obtained by both the participating health care workers before the consultation. A copy of the document should then be given to the patient. Unfortunately, in an asynchronous system time lags would make this impractical. The HPCSA also required a prior doctor-patient relationship; this is problematic, given that previously it was unlikely that rural patients would have consulted with specialists in the city. The rural nature of the Eastern Cape presented further challenges as some of the patients would have had limited exposure to and knowledge of ICT. The patient might not understand how the consultation would be conducted, or how their information would be kept private and confidential.

Another issue was how to define 'informed consent' when health care workers had patients from diverse backgrounds and cultures. Many patients might not even speak the same language as the provider-there were 11 official languages in South Africa. Moreover, many of the indigenous languages did not have words for the technology used in telemedicine or what confidentiality of information entailed.

\section{Professional negligence}

Most health care workers reported to Mr Alexander that they had received little to no training when the telemedicine units were first rolled out, with most learning their telemedicine skills through a process of trial and error.

Mr Alexander felt that the risk of professional negligence could be mitigated when making use of telemedicine through the following criteria:

- Telemedicine must demonstrably improve the quality of care even though the doctor could not see or touch the patient;

- The technology used during the telemedicine session must provide a level of detail comparable to a physical examination. This meant that the onus rested on the doctor to meet the clinical standards set out by the HPCSA;

- The doctor should be trained in how to use the telemedicine system before consultation; 
- There needed to be valid reasons to make use of telemedicine instead of referring the patient to the specialist for a face-to-face consultation;

- The existing standard of care would be achieved or exceeded if telemedicine is used; and

- It was specified who would be held accountable in the event the technology failed.

\section{Reimbursement Issues}

One of the main factors that led to the failure of telemedicine was the inability of the service to become self-sustaining. In order to address this issue, Mr Alexander needed to provide a revenue plan of how telemedicine services would be costed, but there seemed to be no provision for this type of service in the ICD 10 coding used in the public service.

\section{Decision}

Upon reflection, Mr Alexander realised that the implication of ethical and legal issues must be addressed before telemedicine could be rolled out in the Eastern Cape Province. Despite the vast benefits for health care that the technology promises, health care workers must put the interest of their patients first. If they feel that telemedicine cannot protect the privacy of the patient or provide an adequate standard of care, they will not use it.

In preparation for his report to the ECDoH, Mr Alexander included extracts from some of the most pertinent legal documents that apply to telemedicine. These include the Constitution and Bill of Rights which state that:

27(1)(a) "Everyone has the right to have access to ... healthcare services”;

27(2) states that the government must "take reasonable legislative and other measures ... to achieve the progressive realisation of that right.”

The Constitution therefore clearly stated that the government needed to make provision for healthcare services and put in place the legislation that would govern services such as telemedicine. However, $\mathrm{Mr}$ Alexander knew that the telemedicine policy was never completed. Instead, it was superseded in 2012 with a much more generic version called the e-Health policy for South Africa.

Next, Mr Alexander turned to the HPCSA, a governing and statuary body that provided certification for all doctors in South Africa. The HPCSA (2017) defined telemedicine as:

The exchange of information amongst healthcare professionals at a distance to facilitate, improving and enhancing clinical, educational and scientific healthcare and research, particularly to the under-serviced areas in the Republic of South Africa.

This definition has been criticised previously as it did not refer to ICT specifically. At present, any communication, such as sending a patient file or prescription from one department to another within the same hospital, could be classified as telemedicine as long as the doctors were not in the physical vicinity of each other.

The HPCSA (2017) further stated that "Telemedicine consultations should be restricted to situations in which a healthcare professional is unable, due to geographical constraints or resources to participate in an actual face-to-face consultation,” and that “...telemedicine should be restricted to situations in which a 
previously existing healthcare-patient relationship enabled the healthcare practitioner to gather sufficient knowledge of the patient's clinical condition ...”.

While the first condition could be overcome as telemedicine was able to increase access to health care resources that were not previously available in the rural areas of the Eastern Cape, the second condition meant that the patient should have consulted and had a prior relationship with the specialist. In $\mathrm{Mr}$ Alexander's opinion, this was unlikely to be the case in the Eastern Cape due to the rural nature and long distances that patients must travel in order to access specialist health care. In his opinion, these restrictive conditions that the HPCSA put in place for telemedicine would significantly limit the expansion of the service.

$\mathrm{Mr}$ Alexander has been mandated to roll out telemedicine, starting with teleradiology, across the province during the year that followed. He had completed his analysis of the reasons why telemedicine failed a decade earlier and was determined not to repeat the same mistakes. However, the implementation issues surrounding telemedicine also had to be addressed if telemedicine was to become a fully integrated service of the ECDoH. How should he go about addressing these issues within the legal and statutory frameworks that governed such issues?

\section{References}

Banach, L. (2007). Ten years of Telemedicine in the Eastern Cape Province of South Africa: Facts and Challenges. In: Proceedings of the $1^{\text {st }}$ International Telemedicine conference: Myths and Reality, 8-9 November 2007, Lviv, Ukraine.

Cilliers, L., Flowerday, S (2012). Technology acceptance of Telemedicine in the Eastern Cape Department of Health. Presented at IST-Africa 2012, Tanzania, ISBN 978-1-905824-38-0

Cilliers, L., Flowerday, S (2011). Will computer literacy affect Telemedicine Acceptance among health care workers? Presented at: ResNes Conference, East London. ISBN 978-0-620-51804-8

Cilliers, L., Flowerday, S. (2014). User Acceptance of Telemedicine by Health Care Workers: A case of the Eastern Cape Province, South Africa. Electronic Journal of Information Systems in Developing Countries, 65 (5), pp. 1-10

HPCSA. (n.d) General Ethical Guidelines for Good Practice in Telemedicine: Discussion document. Available at: http://www.hpcsa.co.za/downloads/.../rules/...rules/booklet_1_guidelines_good_prac.pdf (Retrieved 30 July 2016).

Finn, R. L., Wright, D., and Friedewald, M. (2013). Seven types of privacy. In: European Data Protection: Coming of Age (pp. 3-32). Netherlands: Springer.

Gorea, RK. (2005). Legal aspects of telemedicine: telemedical jurisprudence. JPAFMAT, 5, 1-3.

HPCSA. (2017). Conduct and Ethics - booklet 10. Pretoria: HPCSA.

Mars, M. \& Jack, C. (2012). Telemedicine Regulation - How Not To Do It: A South African Experience. Department of TeleHealth, Nelson R Mandela School of Medicine, University of KwaZulu-Natal. Available at: https://www.medetel.eu/download/2012/parallel.../Telemedicine_Regulation.pdfhttps://www.med etel.eu/download/2012/parallel.../Telemedicine_Regulation.pdf (Retrieved 31 July 2016). 
Motsoaledi, M. (2010). Speaking notes for Dr A.P Motsoaledi for the 1st Southern African Telemedicine Conference, Available at: http://www.doh.gov.za/show.php?id=2104 (Retrieved 31 July 2016).

Mxoli, A., Mostert-Phipps, N., and Gerber, M. (2014). Personal Health Records: design considerations for the South African context. Presented at DDR 2014, Cape Town, 8-10 September 2014.

O’Mahony, D., and Wright, G. (2014) Tablet computers for recording tuberculosis data at a community health centre in King Sabata Dalindyebo Local Municipality, Eastern Cape: a proof of concept report. South African Family Practice, 56, 3, pp. 186-189, DOI: 10.1080/20786204.2014.936666.

O’Mahony, D., Wright G., Yogeswaran, P., and Govere, F. (2014). Knowledge and attitudes of nurses in community health centres about electronic medical records. Curationis, 37(1), Art.\#1150, pp. 1-6 pages. Available at http://dx.doi.org/10.4102/curationis.v37i1.1150

Prinsloo, A. (2015). Telemedicine offers new hope for South Africa. Available at http://www.news24.com/ (Retrieved 25 July 2016).

StatsSA. (2012). Key Results: Census 2011. Available at http://www.statsssa.gov.za/Census2011/.../Census_2011_Key_Results.pdf (Retrieved 15 August 2016).

WHO. (2012) E-Health, Available at http://www.who.int/trade/glossary/story021/en/index.html (Retrieved 16 August 2016).

Yerramilli, P. (2015). South Africa's quadruple burden of disease. Retrieved April 24, 2016, from PLOS: http://blogs.plos.org/globalhealth/2015/03/southafrica_quadrupleburden

\section{Biographies}

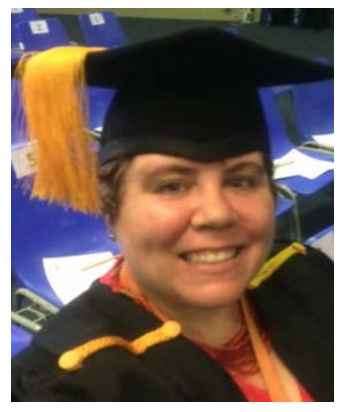

Dr Liezel Cilliers is a Senior Lecturer in the Department of Information Systems at the University of Fort Hare. She holds a DPhil (Information Systems) and the Postgraduate Diploma in Higher Education. In 2016 she was awarded the Vice Chancellor's Excellence award in the category of experienced Teacher. She is also involved in the Health Informatics research group in the Health Science Faculty. Her research areas include technology in education, e-health and health informatics. 


\section{Exhibit 1: Privacy in Telemedicine}

Finn, Wright \& Friedewald (2013) identified several categories of privacy which relate to telemedicine, which include:

- $\quad$ Privacy of the Person - Individuals have the right to keep body functions and characteristics private;

- $\quad$ Privacy of behaviour and action - Individuals have the right to keep sensitive information such as sexual orientation and health behaviour private;

- $\quad$ Privacy of communication -The interception of all an individual's communication including telephonic or wireless communications used in telemedicine;

- $\quad$ Privacy of data and image - Concerns with making sure that an individual's data is not automatically available to other unauthorised individuals and organisations;

- $\quad$ Privacy of location and space - Individuals have the right to move about in public or semi-public spaces without being identified, monitored or tracked in order to access health care services. 